\title{
Reaction of hydroxylated naphtoquinones/antraquinones with pentafluoropyridine
}

\author{
Khalil Beyki, Reza Haydari ${ }^{*}$ and Malek Taher Maghsoodlou
}

\begin{abstract}
In this study, the reaction of pentafluoropyridine with hydroxylated naphtoquinones and hydroxylated antraquinones was investigated under basic conditions in DMF. One or two hydroxyl group in naphtoquinones and antraquinones react with pentafluoropyridine to give mono and di-tetrafluoropyridyl naphtoquinones/antraquinones. All the compounds were characterized using ${ }^{1} \mathrm{H},{ }^{13} \mathrm{C}$ and ${ }^{19} \mathrm{~F}$-NMR spectroscopy.
\end{abstract}

Keywords: Pentafluoropyridine, Synthesis, Hydroxylated naphtoquinones, Hydroxylated antraquinones

\section{Background}

Recently, organofluorine compounds have been used as building blocks in the pharmaceutical industry and in material science due to their unique properties (Matthew et al. 2010). In pharmacology and medicinal researches, it is common to substitute hydrogen with fluorine atom for increasing the lipophilicity and the biological activity of drugs (Anatoliy et al. 2009). Various multi-functional pyridine derivatives and the construction of new heterocyclic drug systems could be accessed from the high electron efficiency of pentafluoropyridine and appropriate nucleophile in simple reaction conditions (Satoru et al. 2006; Cindy et al. 2010). The reactions of pentafluoropyridine with nucleophiles occurs in the most activated 4-position of pentafluoropyridine to give products arising from the substitution of fluorine, located para to ring nitrogen to give a range of 4-substituted tetrafluoropyridine systems (Mark et al. 2012). Previously, we reported the synthesis of 4-substituted 2,3,5,6-tetrafluoropyridine derivatives by the reaction of pentafluoropyridine with malononitrile, 1-tetrazole-5-thiol, and piperazine (Beyki et al. 2015). In this paper, we have recently reported the

*Correspondence: heydari@chem.usb.ac.ir Department of Chemistry, Faculty of Science, University of Sistan and Baluchestan, P. O. Box 98135-674, Zahedan, Iran reaction of pentafluoropyridine with a very important class of biologically active compounds (Elias and Alexandros 2002), hydroxylated naphtoquinones and hydroxylated antraquinones. This allows the synthesis of a wide range of 4-substituted tetrafluoropyridine.

\section{Results and discussion}

The reaction of pentafluoropyridine $\mathbf{1}$ with an equivalent of 5,8-dihydroxynaphthalene-1,4-dione 2 in the presence of potassium carbonate in DMF gave a mixture of two products, $\mathbf{2} \mathbf{a}$ and $\mathbf{2 b}$ arising from the displacement of the 4-fluor pyridine ring with naphtoquinones.

In hydroxylated naphtoquinones 2 , the hydroxyl group deprotonates by potassium carbonate and attacks the para position of pentafluoropyridine to give 2a (Fig. 1). In $\mathbf{2 b}$, both hydroxyl groups deprotonate and attack the para position of the pentafluoropyridine. The purification of $\mathbf{2 a}$ and $\mathbf{2 b}$ was achieved by column chromatography using ethyl acetate/n-hexane (1:10). The identification of 2a was done by ${ }^{19} \mathrm{~F}$ NMR analysis, in which the resonance attributed to the fluorine located in ortho ring nitrogen has a chemical shift of $-87.6 \mathrm{ppm}$ and the fluorine located in meta to ring nitrogen occurs at $-162.0 \mathrm{ppm}$. The two resonances by ${ }^{19} \mathrm{~F}$ NMR and their chemical shift indicate the displacement of fluorine atoms attached to the para position of pyridine ring. In ${ }^{1} \mathrm{H}$ NMR of $\mathbf{2 a}$, the

\section{Springer}

(C) 2016 Beyki et al. This article is distributed under the terms of the Creative Commons Attribution 4.0 International License (http://creativecommons.org/licenses/by/4.0/), which permits unrestricted use, distribution, and reproduction in any medium, provided you give appropriate credit to the original author(s) and the source, provide a link to the Creative Commons license, and indicate if changes were made. 


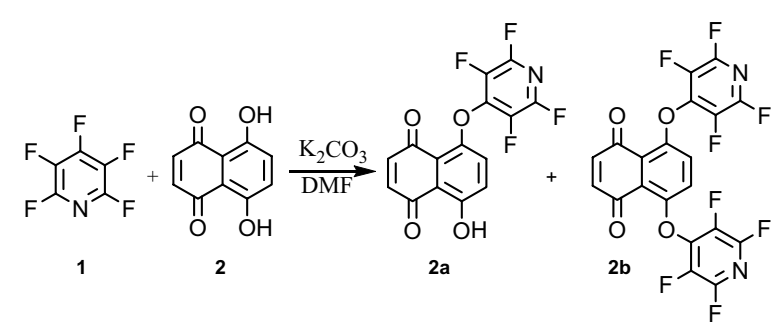

Fig. 1 Reaction of pentafluoropyridine with 5,8-dihydroxynaphthalene-1,4-dione

protons of the phenyl ring were observed at $\delta=7.2-8.1$ and hydroxyl group $(\mathrm{OH})$ at $6.1 \mathrm{ppm}$. The mass spectrum of $\mathbf{2 a}$ displayed the molecular ion peak $\left(\mathrm{M}^{+}\right)$ at $\mathrm{m} / \mathrm{z}=339$, which is consistent with the proposed structure.

In $\mathbf{2 b},{ }^{19} \mathrm{~F}$ NMR spectroscopy shows two resonances at -83.5 and $-84.3 \mathrm{ppm}$ attributed to the fluorine located in the ortho position of the two ring nitrogen and the two resonances at -135.4 and $-139.4 \mathrm{ppm}$ attributed to the fluorine located in the meta position of two tetrafluoropyridine. In $\mathbf{2 b}$, the four resonances by ${ }^{19} \mathrm{~F}$ NMR indicate the two rings of pentafluoropyridine displacement of fluorine atoms at the para positions of pyridine rings. The ${ }^{1} \mathrm{H},{ }^{13} \mathrm{C}$ NMR confirmed the structure of $\mathbf{3 b}$. The protons of the phenyl ring were observed at $7.2 \mathrm{ppm}$. In MS spectrum, the molecular ion $\mathrm{M}^{+}+1$ at $\mathrm{m} / \mathrm{z}=490$ was observed.

The reaction of pentafluoropyridine $\mathbf{1}$ with an equivalent of 1,4-dihydroxyanthracene-9,10-dione 3 in the presence of potassium carbonate as the base in DMF solvent gave 3c and 3d in 41 and $11 \%$ yield respectively (Fig. 2). In 3c, a hydroxyl group of $\mathbf{3}$ attacks the para position of the pyridine ring, and in $\mathbf{3 d}$, the two hydroxyl groups attack the most activated para position of pentafluoropyridine. The purification of 3c and 3d was achieved by column chromatography using ethyl acetate/n-hexane (1:10). The identification of $\mathbf{3 c}$ was done from the ${ }^{19} \mathrm{~F}$ NMR analysis in which the resonance attributed to the fluorine atom located in the ortho positions had a chemical shift of $-88.2 \mathrm{ppm}$. The corresponding resonance for the meta to ring nitrogen in 3c occurs at $-158.1 \mathrm{ppm}$. The ${ }^{1} \mathrm{H}$ NMR spectra of compound 3c showed an $\mathrm{H}$ broad signal at $4.2 \mathrm{ppm}$ for $\mathrm{OH}$ group, and the protons of the phenyl ring were observed at $\delta=7.2-8.3 \mathrm{ppm}$. In the MS spectrum of $\mathbf{3 c}$, the molecular ion $\mathrm{M}^{+}$at $\mathrm{m} / \mathrm{z}=389$ was observed.

Mass spectrometry and ${ }^{19} \mathrm{~F}$ NMR confirmed the product of $\mathbf{3 d}$ as a di-tetrafluoropyridine system. The ${ }^{19} \mathrm{~F}$ NMR 3d showed two resonances at -87.5 and $-91.8 \mathrm{ppm}$ attributed to the fluorine located in the ortho to ring nitrogen and the two resonances at -156.5 and $-162.6 \mathrm{ppm}$ attributed to the meta to ring nitrogen. Other spectroscopic techniques were consistent with the structures proposed. In ${ }^{1} \mathrm{H}$ NMR, the spectra protons of the phenyl ring were observed at 7.5-8.7 ppm. The mass spectrum of 3d displayed the molecular ion peak $\left(\mathrm{M}^{+}\right)$at $\mathrm{m} / \mathrm{z}=538$, which is consistent with the proposed structure.

Also, we observed that the reaction of pentafluoropyridine 1 with 1,8-dihydroxyanthracene-9,10-dione 4 in the presence of potassium carbonate in DMF solvent gave $\mathbf{4 e}$. In basic conditions, the hydroxyl group of $\mathbf{4}$ deprotonation and attack on the para position of pentafluoropyridine gave $4 \mathbf{e}$ (Fig. 3). The structure of compounds $4 \mathbf{e}$ was confirmed by the NMR spectroscopic data and the MS analysis. In particular, the ${ }^{19} \mathrm{~F}$ NMR spectroscopy showed the chemical shift of fluorine atoms attached to the ortho and the meta position, observed respectively at -91.6 and $-142.5 \mathrm{ppm}$. In ${ }^{1} \mathrm{H} \mathrm{NMR}$, the protons of $\mathrm{OH}$ were observed at $4.2 \mathrm{ppm}$, and the protons of the phenyl ring were observed at 7.0-8.2 ppm. In the MS spectrum, the molecular ion $\mathrm{M}^{+}$at $\mathrm{m} / \mathrm{z}=389$ was observed.

\section{Conclusion}

We showed that one or two hydroxyl groups in hydroxylated naphtoquinones and hydroxylated antraquinones can react with the pentafluoropyridineto afford of mono and di-2,3,5,6-tetrafluoropyridine naphtoquinones/ antraquinones.

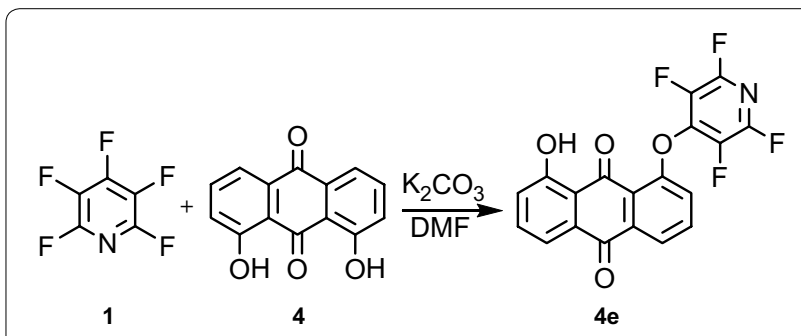

Fig. 3 Reaction of pentafluoropyridine with 1,8-dihydroxyanthracene-9,10-dione

Fig. 2 Reaction of pentafluoropyridine with 1,4-dihydroxyanthracene-9,10-dione 


\section{Experimental}

All materials and solvents were purchased from Merck and Aldrich and were used without any additional purification. The melting points of the products were determined in open capillary tubes using BAMSTEAB Electrothermal apparatus model 9002. Mass spectra were taken by a Micro mass Platform II: EI mode $(70 \mathrm{eV})$. Silica plates (Merck) were used for TLC analysis.

\section{Preparation of 5-hydroxy-8-(perfluoropyridin-4-yloxy) naphthalene-1,4-dione $2 \mathrm{a}$ and 5,8-bis(perfluoropyridin-4-y loxy)naphthalene-1,4-dione $2 \mathrm{~b}$}

Pentafluoropyridine 1 (0.16 g, $1 \mathrm{mmol})$, 5,8-dihydroxynaphthalene-1,4-dione $2(0.19 \mathrm{~g}, 1 \mathrm{mmol})$ and potassium carbonate $(0.11 \mathrm{~g}, 1.0 \mathrm{mmol})$ were stirred together in DMF $(5 \mathrm{~mL})$ at reflux temperature for $8 \mathrm{~h}$. After completion of the reaction (indicated by TLC), reaction mixture was evaporated to dryness and water $(10 \mathrm{~mL})$ was added and extracted with dichloromethane $(2 \times 10 \mathrm{~mL})$ and ethylacetate $(2 \times 10 \mathrm{~mL})$. The mixture was filtered, volatiles evaporated and the residue purified by column chromatography on silica gel using ethyl acetate/n-hexane (1:10).

5-hydroxy-8-(perfluoropyridin-4-yloxy)naphthalene-1,4-dione $2 \mathrm{a} \quad(0.1 \mathrm{~g}, 29 \%)$ as an orange solid; $\mathrm{mp}$ $240{ }^{\circ} \mathrm{C} \mathrm{dec} ;{ }^{1} \mathrm{H}$ NMR $\left(\mathrm{CDCl}_{3}\right): \delta(\mathrm{ppm}) 4.1(1 \mathrm{H}, \mathrm{s}, \mathrm{OH})$, 7.2-8.3 (4H, m, Ar-H), ${ }^{19} \mathrm{~F}$ NMR (DMSO): $\delta(\mathrm{ppm})$ -87.6 (2F, s, F-2,6), -162.0 (2F, s, F-3,5), ${ }^{13} \mathrm{C}$ NMR $\left(\mathrm{CDCl}_{3}\right): \delta$ (ppm) 115.3, 117.2, 119.7, 120.3, 125.4, 128.3, 131.0, 137.5, 150.3, 159.2, 169.2, 170.1, 171.8, MS (EI), $\mathrm{m} / \mathrm{z}(\%)=341\left(\mathrm{M}^{+}\right)(32 \%) 318,309,301,291,272,255$, 246, 224, 198, 180, 152, 126, 106, 86, 58, 44.

5,8-bis(perfluoropyridin-4-yloxy)naphthalene-1,4-dione 2b $(0.08 \mathrm{~g}, 16 \%)$ as an orange/yellow solid; $\mathrm{mp} 330{ }^{\circ} \mathrm{C}$ dec; ${ }^{1} \mathrm{H}$ NMR $\left(\mathrm{CDCl}_{3}\right): \delta(\mathrm{ppm}) 7.2(5 \mathrm{H}, \mathrm{m}, \mathrm{Ar}-\mathrm{H}),{ }^{19} \mathrm{~F}$ $\operatorname{NMR}\left(\mathrm{CDCl}_{3}\right): \delta(\mathrm{ppm})-83.5(2 \mathrm{~F}, \mathrm{~s}, \mathrm{~F}-2,6),-84.2(2 \mathrm{~F}, \mathrm{~s}$, $\left.\mathrm{F}-2^{\prime}, 6^{\prime}\right),-135.4$ (2F, s, F-3,5), $-139.4\left(2 \mathrm{~F}, \mathrm{~s}, \mathrm{~F}-3^{\prime}, 5^{\prime}\right) .{ }^{13} \mathrm{C}$ $\mathrm{NMR}\left(\mathrm{CDCl}_{3}\right): \delta$ (ppm) 91.8, 128.8, 130.9, 178.0, MS (EI), $\mathrm{m} / \mathrm{z}(\%)=490\left(\mathrm{M}^{+}+2\right)(25 \%), 461,443,409,384,369$, $350,331,318,302,268,255,239,212,181,167,149,136$, 104, 90, 77, 57, 43.

\section{Preparation of 1-hydroxy-4-(perfluoropyridin-4-yloxy) anthracene-9,10-dione $3 \mathrm{c}$ and 1,4-bis(perfluoropyridin-4-y loxy)anthracene-9, 10-dione 3d}

Pentafluoropyridine 1 (0.16 g, $1 \mathrm{mmol})$, 1,4-dihydroxyanthracene-9,10-dione $3(0.24 \mathrm{~g}, 1 \mathrm{mmol})$ and potassium carbonate $(0.11 \mathrm{~g}, 1.0 \mathrm{mmol})$ were heated in DMF $(5 \mathrm{~mL})$ at reflux for $12 \mathrm{~h}$ (monitored by TLC). After completion of the reaction, the solvent was evaporated to dryness; water $(10 \mathrm{~mL})$ was added and extracted with dichloromethane $(2 \times 10 \mathrm{~mL})$ and ethylacetate $(2 \times 10 \mathrm{~mL})$. The mixture was filtered, volatiles evaporated and the residue purified by column chromatography on silica gel using ethyl acetate/n-hexane (1:10).

1-hydroxy-4-(perfluoropyridin-4-yloxy)anthracene-9,10-dione 3c $(0.16 \mathrm{~g}, 41 \%)$ as a yellow solid; $\mathrm{mp}$ $355{ }^{\circ} \mathrm{C} \mathrm{dec} ;{ }^{1} \mathrm{H}$ NMR $\left(\mathrm{CDCl}_{3}\right): \delta(\mathrm{ppm}) 4.1(1 \mathrm{H}, \mathrm{s}, \mathrm{OH})$, 7.2-8.3 (6H, m, Ar-H), ${ }^{19} \mathrm{~F} \mathrm{NMR}\left(\mathrm{CDCl}_{3}\right): \delta(\mathrm{ppm})-88.2$ (2F, s, F-2,6), $-158.1(2 \mathrm{~F}, \mathrm{~s}, \mathrm{~F}-3,5),{ }^{13} \mathrm{C}$ NMR $\left(\mathrm{CDCl}_{3}\right): \delta$ (ppm) 126.5, 127.0, 133.6, 133.9, 138.8, 145.4, 148.5, 160.9, 188.9, MS (EI), m/z (\%) = $389(\mathrm{M}), 371,354,340$, $321,307,290,263,237,212,195,181,157,143,125,112$, $91,77,57,43$.

1,4-bis(perfluoropyridin-4-yloxy)anthracene-9,10-dione 3d $(0.06 \mathrm{~g}, 11 \%)$ as a red/black solid; $\mathrm{mp} 315^{\circ} \mathrm{C}$ dec; ${ }^{1} \mathrm{H}$ NMR $\left(\mathrm{CDCl}_{3}\right): \delta(\mathrm{ppm}) 4.2(1 \mathrm{H}, \mathrm{s}, \mathrm{OH}), 7.2-8.7(6 \mathrm{H}, \mathrm{m}$, Ar-H), ${ }^{19} \mathrm{~F}$ NMR $\left(\mathrm{CDCl}_{3}\right): \delta(\mathrm{ppm})-87.5(2 \mathrm{~F}, \mathrm{~s}, \mathrm{~F}-2,6)$, -91.8 (2F, s, F-2',6'), -156.5 (2F, s, F-3,5), -162.6 (2F, s, $\left.\mathrm{F}-3^{\prime}, 5^{\prime}\right),{ }^{13} \mathrm{C}$ NMR $\left(\mathrm{CDCl}_{3}\right): \delta(\mathrm{ppm}) 120.9,122.2,123.4$, 123.6, 124.5, 127.1, 128.5, 129.1, 130.1, 132.4, 136.5, 139.2, 140.4, 146.4, 147.4, 166.1, 170.2, MS (EI), m/z $(\%)=538(\mathrm{M}), 496,480,439,411,398,384,362,347,331$, 316, 302, 283, 270, 255, 239, 225, 209, 196, 181, 167, 154, 129, 105, 86, 57, 43.

\section{Preparation of 1-hydroxy-8-(perfluoropyridin-4-yloxy) anthracene-9,10-dione 4e}

Pentafluoropyridine 1 (0.16 g, $1 \mathrm{mmol})$, 1,8-dihydroxyanthracene-9,10-dione $4(0.24 \mathrm{~g}, 1 \mathrm{mmol})$ and potassium carbonate $(0.11 \mathrm{~g}, 1.0 \mathrm{mmol})$ were heated in DMF $(5 \mathrm{~mL})$ at reflux for $12 \mathrm{~h}$ (monitored by TLC). After completion of the reaction, the solvent was evaporated to dryness; water $(10 \mathrm{~mL})$ was added and extracted with dichloromethane $(2 \times 10 \mathrm{~mL})$ and ethylacetate $(2 \times 10 \mathrm{~mL})$. The mixture was filtered, volatiles evaporated and the residue purified by column chromatography on silica gel using ethyl acetate/n-hexane (1:8).

1-hydroxy-8-(perfluoropyridin-4-yloxy)anthracene-9,10-dione 4e (0.09 g, $23 \%)$ as a red solid; mp $340{ }^{\circ} \mathrm{C} \mathrm{dec} ;{ }^{1} \mathrm{H}$ NMR $\left(\mathrm{CDCl}_{3}\right): \delta(\mathrm{ppm}) 4.3(1 \mathrm{H}, \mathrm{s}, \mathrm{OH})$, 7.1-8.0 (6H, m, Ar-H), ${ }^{19} \mathrm{~F} \mathrm{NMR}\left(\mathrm{CDCl}_{3}\right): \delta(\mathrm{ppm})-91.6$ (2F, s, F-2,6), $-162.5(2 \mathrm{~F}, \mathrm{~s}, \mathrm{~F}-3,5),{ }^{13} \mathrm{C}$ NMR $\left(\mathrm{CDCl}_{3}\right): \delta$ (ppm) 120.9, 122.2, 123.2, 123.6, 124.5, 127.1, 128.8, $130.2,130.9,131.2,132.4,136.5,139.2,140.4,146.4$, 147.9, 161.0, 164.0, 167.8. MS (EI), $\mathrm{m} / \mathrm{z}(\%)=389\left(\mathrm{M}^{+}\right)$, 
$387,370,364,360,342,316,299,281,255,240,223,202$, $184,169,155,141,127,101,79,57,43$.

\section{Authors' contributions}

Study conception and design: The reaction of pentafluoropyridine with5,8dihydroxynaphthalene-1,4-dione, 1,4-dihydroxyanthracene-9,10-dione and 1,8-dihydroxyanthracene-9,10-dione to give highly fluorinated heterocyclic materials. The attractive of this protocol are cleaner reaction, non-toxic catalyst which makes it a useful and attractive process for the preparation of 4-substituted-tetra fluoropyridine. Acquisition of data: from articles and books. Analysis and interpretation of data: by RH and KB. Drafting of manuscript: KB. Critical revision: MTM. All authors read and approved the final manuscript.

\section{Acknowledgements}

Financial support from the Research Council of the University of Sistan and Baluchestan is gratefully acknowledged.

\section{Competing interests}

The authors declare that they have no competing interests.

Received: 9 September 2015 Accepted: 12 January 2016

Published online: 01 February 2016

\section{References}

Anatoliy MS, Ludmila AR, Alexander EF, Victor EK, Kirill GN, Alexandr AS, Andrei AG (2009) Synthesis of 3-cyano-2-fluoropyridines. J Fluor Chem 130:236-240

Beyki K, Haydari R, Maghsoodlou MT (2015) Synthesis of 2,3,5,6-tetrafluoro-pyridine derivatives from reaction of pentafluoropyridine with malononitrile, piperazine and tetrazole-5-thiol. SpringerPlus 4:757

Cindy C, Stéphane C, Alexandre R, Karine V, Jean-Dominique C, François M, Sylvette $B$ (2010) Fluorination of 2-chloropyridine over metal oxide catalysts as new catalytic fluorination systems. Catal Commun 12:151-153

Elias AC, Alexandros TS (2002) Generation of libraries of pharmacophoric structures with increased complexity and diversity by employing polymorphic scaffolds. Eur J Org Chem 3341:3350

Mark AF, Graham S, Rachel S, Dmitrii SY, Judith AKH, Antonio V (2012) Reactions of 4-substituted tetrafluoropyridine derivatives with sulfur nucleophiles: $\mathrm{S}_{\mathrm{N}} \mathrm{Ar}$ and annelation processes. J Fluor Chem 143:148-154

Matthew WC, Emma LP, Graham P, Rachel S, Graham S, lan W, Dmitrii SY, Judith AKH, John AC, David DM (2010) Annelation of perfluorinated heteroaromatic systems by 1,3-dicarbonyl derivatives. Tetrahedron 66:3222-3227

Satoru A, Tsutomu K, John TG, Takashi I, Hiroki Y (2006) Synthetic application of fluorinated vinamidinium salts: synthesis of fluorinated 1,3-butadienylphosphonates by the reaction with Horner-Wadsworth-Emmons reagents. J Fluor Chem 127:1235-1241

\section{Submit your manuscript to a SpringerOpen ${ }^{\odot}$ journal and benefit from:}

- Convenient online submission

- Rigorous peer review

- Immediate publication on acceptance

- Open access: articles freely available online

- High visibility within the field

- Retaining the copyright to your article

Submit your next manuscript at springeropen.com 